\title{
Foraging ecology of tropicbirds breeding in two contrasting marine environments in the tropical Atlantic
}

Ngoné Diop $1,2,{ }^{*}$, Laura Zango2, Annalea Beard3, Cheikh Tidiane Ba1, Papa Ibnou

Ndiaye1, Leeann Henry3, Elizabeth Clingham 3 , Steffen Oppel4, Jacob González-Solís2

Department of Animal Biology, Cheikh Anta Diop University, Av Cheikh Anta Diop, Dakar 5005, Senegal

Institut de Recerca de la Biodiversitat (IRBio) and Department de Biologia Evolutiva, Ecologia i Ciències Ambientals (BEECA), Universitat de Barcelona, Av Diagonal 643, Barcelona 08028, Spain

${ }_{3}$ Marine Section, Environmental Management Division of the Environmental and Natural Resources Directorate, St Helena Government, Essex House, Jamestown STHL 1ZZ, St Helena Island, South Atlantic

${ }_{4}$ RSPB Centre for Conservation Science, The David Attenborough Building, Pembroke Street, Cambridge CB2 3QX, UK

*Corresponding author: ngone04@hotmail.fr

This is the accepted manuscript of a paper originally published in Marine Ecology Progress Series. You may find the final, formatted version at 10.3354/meps12774.

\section{ABSTRACT:}

Studying the feeding ecology of seabirds is important not only to understand basic aspects of their ecology and threats but also for the conservation of marine ecosystems. In this regard, tropical seabirds have been relatively neglected, and in particular the trophic ecology of tropicbirds is scarcely known. We combined GPS tracking, environmental variables and sampling of regurgitates during incubation and brooding to understand the feeding ecology of red-billed tropicbirds Phaethon aethereus as well as how foraging strategies may change between 2 contrasting marine environments: a coastal island in the Canary Current upwelling (lles de la Madeleine) and an oceanic island in the middle of the south Atlantic (St Helena). Tropicbirds breeding on the lles de la Madeleine headed west, foraging on and beyond the shelf slope, probably to associate with subsurface predators which bring pelagic fish close to the surface. Birds from St Helena showed a greater foraging effort and a strong attraction to areas with the greatest species richness of Scombridae, possibly due to a greater difficulty in finding prey in the oligotrophic oceanic waters. Tropicbirds ranged much beyond the extension of the protected areas around their colonies, indicating that current protected areas are 
insufficient for these populations. We found no evidence to suspect direct mortality of tropicbirds in regional fisheries, but overexploitation of small epipelagic fish and tuna may decrease feeding opportunities and lead to competition with fisheries. The substantial differences in foraging behaviour demonstrated by individuals from both colonies indicates that caution should be taken when extrapolating foraging patterns of tropical seabirds breeding in contrasting oceanographic environments.

\section{INTRODUCTION}

The different aspects of the feeding ecology of seabirds, such as diet, activity patterns, foraging movements and feeding habitat selection, should ideally be studied in parallel. Doing so can allow a better understanding of the main dimensions of the trophic niche as well as the main factors affecting seabird diet and movements. However, this knowledge is still lacking for many species, particularly among tropical seabirds. In tropical waters, daytime foraging is often related to associations with subsurface predators, such as tunas and, to a lesser extent, cetaceans, which bring the fish close to the surface and create feeding opportunities for oceanic sea- birds (Spear et al. 2007, Miller et al. 2018). On the other hand, diel vertical migrations are thought to be particularly important in oceanic environments, with many fish and marine invertebrate species being accessible for seabirds mainly during crepuscular hours (Pinet et al. 2012, Pollet et al. 2014). A number of studies related the occurrence of fish and invertebrates known to perform diel vertical migrations in the diet of seabirds to crepuscular foraging, but direct evidence is scarce and somewhat controversial (Spear et al. 2007). In this context, combining the information obtained from tracking devices on the feeding grounds and daily activity with diet samples from regurgitations offers an excellent opportunity to understand when and where the different prey is taken, the diurnal or nocturnal feeding strategies or the use of neritic versus oceanic waters. In addition, this approach is especially useful for our understanding of whether direct or indirect interactions with fisheries occur (Bertrand et al. 2012, Lewison et al. 2012). Direct interactions occur when seabirds take advantage of fishery discards mainly from trawlers or are caught as by-catch in longline fishing gear, whereas indirect interactions are when seabirds compete with fisheries who tar- get their prey, such as purse-seine fishing or some small artisanal fisheries.

GPS tracking data can also be used in combination with environmental variables of the marine habitat to understand how environmental conditions can influence foraging strategies and feeding habitat selection (Wakefield et al. 2009). These relationships have been used to predict important areas for colonies whose seabirds have not been previously tracked (e.g. Torres et al. 2015, Wakefield et al. 2017, Péron et al. 2018, Yates et al. 2018). However, these pre- dictions are expected to fit better in areas with similar and persistent oceanographic features, such as upwellings, which may provide highly predictable resources (Mannocci et al. 2014). In this context, the association between tropical seabirds and the marine habitat is possibly less intense, since tropical areas are more oligotrophic and less predictable than temperate or polar ones (Weimerskirch 2007, Oppel et al. 2017). However, recent work on tropical shear- waters suggests that tropical seabirds show a tighter association to environmental features than previously thought (McDuie et al. 2018, Miller et al. 2018). Nevertheless, whether it 
is feasible to infer seabird foraging patterns from untracked colonies based on habitat preference in tropical systems is still uncertain.

In tropicbirds, some studies have focussed on diet composition, diving depths, duration of foraging trips and feeding frequency, but mainly in the Indian Ocean and the Pacific (Le Corre 1997, Le Corre et al. 2003, Spear et al. 2007, Sommerfeld \& Hennicke 2010). In tropical areas, solitary medium- and small- sized procellariforms typically show important nocturnal activity, whereas tropicbirds are usually considered diurnal feeders (Spear et al. 2007, Sommerfeld \& Hennicke 2010). However, typically diurnal seabirds, such as Cory's shearwaters Calonectris diomedea, have been found to have some plasticity in their diurnal-nocturnal foraging depending on the habitat exploited (Dias et al. 2012); therefore, the assumption of diurnal feeding of tropicbirds deserves some attention. Tropicbirds have not been tracked with high-resolution GPS devices until very recently (Soanes et al. 2016, Campos et al. 2018), and little is known about their feeding ecology and movements at sea. Red-billed tropicbirds Phaethon aethereus have a small, pantropical population of fewer than 8000 pairs, occurring in the western Pacific, Atlantic and northern Indian Oceans (Orta 1992, Lee \& Walsh-McGehee 2000). This species is classified as 'Least Concern' by the IUCN, although its population trend is decreasing (BirdLife International 2018). Studies of red-billed tropicbirds have so far been limited to their breeding phenology and breeding success (Stonehouse 1962, Snow 1965, Harris 1969, Beard et al. 2013) and their abundance and distribution based on boat surveys (Spear \& Ainley 2005a). A single study investigated the foraging ecology of red-billed tropicbirds and other species breeding in Anguilla (eastern Caribbean) to identify important foraging areas in the region (Soanes et al. 2016). However, this study did not focus on understanding the feeding ecology of the species, and therefore basic information on their habitat preferences, daily activity patterns and diet is still lacking.

In this study, we investigated the feeding ecology of red-billed tropicbirds in 2 areas with contrasting marine environments, i.e. the lles de la Madeleine (P. a. mesonauta) and St Helena ( $P$. a. aethereus) (Orta et al. 2016). Madeleine is a coastal island on the African Shelf within a major upwelling system sustaining large fish populations (e.g. Ba et al. 2017, Thiaw et al. 2017). This high prey availability is widely exploited by many pelagic seabirds, both during summer (Ramos et al. 2013, Paiva et al. 2015) and winter (Grecian et al. 2016). St Helena is an oceanic island in the middle of the south Atlantic far from any productive areas. These 2 colonies provide ideal conditions to investigate foraging ecology in the tropical Atlantic and to understand whether the foraging ecology of red- billed tropicbirds changes in relation to the environment, and therefore whether their foraging patterns can be extrapolated across different breeding colonies. In particular, we aimed to (1) characterize the main dimensions of the trophic niche of tropicbirds in the Atlantic, i.e. diet, activity patterns and foraging areas, understand how tropicbirds modulate their foraging behaviour in relation to the breeding stage, the breeding colony and the oceanographic conditions, and understand the implications for conservation, particularly in terms of potential interactions with fisheries, the delineation of marine protected areas and predicting foraging areas across breeding colonies. 


\section{Study area}

This study was carried out on 2 islands in the central eastern Atlantic (Fig. 1):

Madeleine Island in the lles de la Madeleine (from November 2015 to February 2016) and St Helena (from August to December 2015). The national park of lles de la Madeleine $\left(14^{\circ} 39^{\prime} \mathrm{N}, 17^{\circ} 28^{\prime} \mathrm{W}\right)$ is a coastal island of $0.17 \mathrm{~km} 2$ off Senegal on the African continental shelf, less than $100 \mathrm{~km}$ from the shelf break. The continental shelf is shallow $(<100 \mathrm{~m})$. St Helena ( $15^{\circ} 57^{\prime} \mathrm{S}, 5^{\circ} 42^{\prime} \mathrm{W}$ ) is a subtropical oceanic island of 122 $\mathrm{km} 2$ in the middle of the South Atlantic Ocean $1856 \mathrm{~km}$ off the West African coast. The sea is about $100 \mathrm{~m}$ deep within about $2 \mathrm{~km}$ around the island and drops to $3600 \mathrm{~m}$ beyond $2 \mathrm{~km}$ (Prater 2012).

Fig. 1. Location of the 2 study colonies of red-billed tropicbirds (Madeleine and St Helena) in the eastern tropical Atlantic Ocean. Black circles represent nest sites; white arrows indicate north

\section{Ethics}


To understand the effect of GPS tracking on breeding success, of 41 monitored nests on Madeleine, 25 were used to deploy GPS devices on adults and 16 were left

undisturbed. On St Helena, of 24 monitored nests, 12 were used to track adults and the other 12 were not manipulated. To determine the effect of devices on the body condition of some animals were weighed repeatedly) and un- tracked adults ( $N=16)$, as well as 10 chicks from disturbed and 7 from undisturbed nests on Madeleine. To determine potential effects of GPS tracking on the return rate, we compared the return rate to the breeding colony in the following year between tracked and untracked animals by visiting all nests on Madeleine in the next breeding season (data for St Helena not available).

\section{Diet identification through regurgitates}

We were only able to collect spontaneous regurgitates from adults and chicks on Madeleine Island, so these data are only available for this breeding site. Samples were placed individually in a zip bag and kept frozen until analyses. Once in the lab, we cleaned regurgitates with water in 2 metallic sieves of 1 and $2 \mathrm{~mm}$ mesh size. We separated prey items, scales and otoliths from whole fish to help identify the specimens. Most regurgitates contained only partly digested prey, which could be identified with the help of fish guides of the study area (Seret 1981, Bellemans et al. 1988). We calculated the percentage of frequency of each family of prey. We also weighed each prey item to calculate the percentage of bio- mass of each family. In order to have information on the potential competition between tropicbirds and fisheries, we searched for the commercial value of the prey we found in regurgitates and the quantity (in tonnes) of the highest commercial value prey captured by fisheries in the exclusive economic zone (EEZ) of Senegal in 2015.

\section{Foraging trajectory}

We deployed 41 GPS devices on 34 tropicbirds on Madeleine and 24 devices on 13 tropicbirds on St Helena during incubation and early brooding (chicks $<15$ d old) in both colonies. Individual birds were caught by hand in the nest and GPS devices were deployed on each partner, alternately, with a maxi- mum of 2 deployments per individual. GPS devices were programmed to record a signal every 5 min and were water-proofed with heat-shrinking tubing. We deployed modified Mobile Action igotU ${ }^{\mathrm{TM}}$ GT-120 GPS devices to the top surface of the 4 central rectrices, just below the uropygium, with 3 pieces (diameter: $1.5 \mathrm{~cm}$, length: $10 \mathrm{~cm}$ ) and 1 piece (diameter: $2 \mathrm{~cm}$, length: $5 \mathrm{~cm}$ ) of Tesa ${ }^{\mathrm{TM}}$ Tape. The size of the GPS devices was $5.0 \mathrm{~cm}$ (length), $2.2 \mathrm{~cm}$ (width) and $0.8 \mathrm{~cm}$ (height). The GPS device and the Tesa tape (18.25 g) weighed on average up to $3 \%$ of the weight of the tracked bird on Madeleine (average weight $614.62 \pm 6.27$ [SD] g; range 520-720 g; 3\%) and St Helena (average weight $701.66 \pm$ $13.26 \mathrm{~g}$; range 600-900 g; 2.6\%). We recaptured the birds on the nest, recovered the GPS device from 3 to $15 \mathrm{~d}$ after GPS deployment (depending on nest attendance) and downloaded the data.

We used R to filter GPS trajectories, by removing positions on land and erroneous locations (i.e. positions that would have required travel with an average speed of $>80$ 
$\mathrm{km} \mathrm{h}-1$ ). We then split the trajectories with more than 1 foraging trip into respective foraging trips that were delineated by the bird's intermittent return to the colony. For each foraging trip, we calculated the maximum distance from the colony, the total duration of the trip and the distance travelled. We used a Gaussian Mixture Model maximum likelihood estimation algorithm provided in the EMbC package in $R$ to describe 4 types of behaviour (resting, intensive search, extensive search, relocation) (Garriga et al. 2016). The algorithm classifies each type of behaviour based on the speed and the turning angle of the trajectory: resting is low speed, low turning angle; intensive search is low speed, high turning angle; extensive search is high speed, high turning angle; and relocation is high speed, low turning angle. We also used hidden Markov models (HMM) with 4 states to classify locations, as HMMs can be more successful in identifying actual foraging behaviour (Bennison et al. 2018). However, when visually inspecting the classification, we did not find substantial differences between methodologies and we kept the EMbC (see Supplement 1 and Fig. S1 at www.intres.com/articles/suppl/m607p221_supp.pdf). Both EMbC and HMM algorithms often classified locations as intensive search when the bird was actually resting, probably due to the location error of the GPS devices when animals are resting, which resulted in artificially high turning angles with very low speed (see Supplements 2 \& 3 and Figs. S2 \& S3 to understand the reasoning of this conclusion). Therefore, we decided to pool locations classified as intensive search and resting into the same category as 'resting behaviour'. Foraging behaviour was then inferred from locations classified by the EMbC as 'extensive search'.

We used kernel density estimations (KDEs) to transform foraging positions into utilization distributions (Wood et al. 2000) in order to determine the most important foraging areas at each colony. We respectively. To describe the daily habits of the animals, we calculated the percentage of each behaviour for each hour of the day, i.e. we divided each for- aging trip into hourly intervals and estimated the percentage of each behaviour in each hour. We graphed the results using the R package 'gamm4'. We pooled together incubation and brooding since there were no differences in the daily pattern. We only included Madeleine in this analysis, since St Helena data included very few locations at night, possibly as a consequence of water covering the GPS device while resting.

\section{Statistical analyses}

All statistical analyses were carried out with R 3.2.5 (R Core Team 2016). We assessed data for normality and homogeneity of variance with $Q-Q$ plots, Shapiro- Wilks Levene's tests, resulting in the use of para- metric analyses throughout. Non-normal data (e.g. behaviour proportions) were arcsine transformed to approach normality.

To address the effect of GPS devices on hatching and fledging success of tropicbirds, we performed chi-squared tests between manipulated and control groups on Madeleine and St Helena. To address GPS effects on the body condition of chicks, we ran a linear mixed-effects model (LMM) with chick mass as the response variable, manipulated/nonmanipulated nest as a fixed effect and chick age as a random effect. To address the 
GPS effect on adult condition, we performed an LMM with adult mass as the response variable, tracked/non-tracked as a fixed effect and individual as a random effect. LMMs were conducted with the function 'Imer' (package 'Ime4', Bates et al. 2015). We used chi-squared tests to compare the return rate of tracked and non-tracked birds. We also performed chi-squared tests to address the differences in the proportion of families of prey found in regurgitates.

We ran further LMMs with colony and breeding stage (either incubation or brooding) as fixed factors and individual as a random factor, to test variation in resting, foraging and relocation between colonies and breeding stages. We created competing models with all variables and the interaction between fixed factors, and selected the most parsimonious models based on Akaike's information criterion corrected for small sample sizes (AICc) using the function 'dredge' (R package 'MuMIn', Barton 2016). Since we found an interaction between colony and breeding stage, we divided the dataset into subsets to test each parameter in each colony and breeding stage separately, performing LMM with the factor of interest as the fixed factor and individual as the random intercept.

To address the differences in the proportion of resting, foraging and relocation between breeding stages on Madeleine, we performed LMMs with breeding stage as a fixed factor and individual as a random factor. We performed analysis of variance with the size of the $95 \%$ kernel utilization distribution for each foraging trip to test for differences in the size of the foraging area used for tropicbirds from Madeleine and St Helena.

\section{Analysis of environmental relationships}

To test whether locations classified as 'foraging behaviour' differed in oceanographic conditions from those classified as 'travelling behaviour', we first downloaded environmental variables corresponding spatially and temporally with the tracking data from the Env-DATA system in Movebank (Dodge et al. 2013) and from other oceanographic data sources. We downloaded day- and night-time sea surface temperature (SST; $4 \mathrm{~km}$ resolution, monthly aver- age), net primary productivity (NPP, 0.083 degree resolution, monthly average), chlorophyll a concentration (chl a, $4 \mathrm{~km}$ resolution, monthly average), sur- face wind vectors (10 m above ground, from Global Atmospheric Reanalysis of the European Centre for Medium-Range Weather Forecasts, $6 \mathrm{~h}$ average) and ocean depth (from ETOPO1 Global Relief Model). We further downloaded monthly mean bottom temperature, current velocity, the depth of the mixed surface layer, salinity and sea surface height from a global analysis at a 0.25 degree resolution (http:// marine.copernicus.eu/documents/PUM/CMEMS- GLO-PUM-001025.pdf). In addition, we acquired the location of major seamounts from bathymetric charts because they can be hotspots of biodiversity (Morato et al. 2008), and downloaded the species richness of Scombridae, subsurface predatory fish that can drive prey fish species for tropical birds to the surface, from Aquamaps (www.aquamaps.org; Kaschner et al. 2016).

We combined surface wind vectors (zonal and meridional velocities) to calculate wind 
speed (in $\mathrm{m} \mathrm{s}-1$ ), and ignored wind direction given that both colonies have very consistent prevailing wind fields (SE winds at St Helena, NE winds at Madeleine). We combined zonal $(U)$ and meridional $(V)$ current velocities to calculate eddy kinetic energy $(\mathrm{EKE})$ using the standard formula EKE $=1 / 2(\mathrm{U} 2+\mathrm{V} 2)$. We calculated the bathymetric slope for each grid cell using the function 'terrain' in the R package 'raster' based on the depth of surrounding grid cells. For each grid cell, we also calculated the Euclidian distance to the colony and nearest seamount.

For each environmental variable we fitted 2 binomial generalised linear mixed models (GLMMs), examining whether the behavioural state ('foraging' or 'relocating') was related to the environmental variable and varied by colony (environment $\times$ colony interaction), or whether the behavioural state was unrelated to the environmental variable (null model). Each of these 2 models included the breeding status and the colony as a fixed factor, and a random intercept for the individual foraging trip to account for non-independence of locations along the same foraging trip. We then used a likelihood-ratio test to examine whether the environmental differences were supported by the data (Lewis et al. 2011). To assess the explanatory power of the full model, we calculated the variance explained (R2) following Nakagawa \& Schielzeth (2013), and we present mean values and associated standard deviations for each environ- mental variable.

Next, we explored whether all environmental variables together (see Table 4) could reliably distinguish between locations classified as 'foraging' and the general marine environment to assess whether red-billed tropicbirds may select certain environ- mental features for foraging. For this we first down- loaded environmental variables for a regular grid of locations spaced $20 \mathrm{~km}$ apart and covering the entire marine area within the radius corresponding to the maximum foraging travel distance from the colony of red-billed tropicbirds at both colonies using the same data sources in the Env-DATA system in Movebank (Dodge et al. 2013) and the global physical reanalysis. The oceanographic variables obtained from the background locations coincided temporally with the month in which tracking data were obtained at the respective colony.

We tested for correlation between predictor variables and removed 1 of 2 highly correlated $\left(r_{S}>0.7\right)$ variables; on St Helena we found a very strong correlation between NPP and chl $a\left(r_{S}=0.885\right)$ and between day-and night-time SST $\left(r_{S}=0.967\right)$, and therefore removed NPP and night-time SST from further analyses. In Madelaine, we found a very strong correlation between bottom temperature and bathymetry $\left(r_{S}=\right.$ $0.822)$, between bottom temperature and mixed layer depth $\left(r_{S}=-0.710\right)$ and between day- and night-time SST $\left(r_{S}=0.912\right)$, and therefore removed bottom temperature and night-time SST from further analyses. Because there was only a single seamount in the foraging range of red-billed tropicbirds around Madelaine, distance to colony and distance to the seamount were also highly correlated $\left(r_{S}=0.792\right)$; we therefore removed distance to the seamount from further analyses.

We then fitted an algorithmic random forest model to classify locations as either background or foraging locations for each colony separately because this algorithm is a powerful method that can include and account for interactions among many different 
variables (Breiman 2001, Cutler et al. 2007, Hochachka et al. 2007). We fitted this model in the R package 'randomForest' (Liaw \& Wiener 2002) with 1500 trees allowing 3 variables to be tried for each node in each tree, and internally cross-validated the model by using $65 \%$ of data to construct trees and the remaining $35 \%$ to assess the classification success. The importance of variables was assessed via a permutation procedure, where the values of each variable were randomly permuted and the decrease in classification success was calculated (Strobl et al. 2007). We re-scaled the decrease in classification accuracy and present relative variable importance (scaled to $100 \%$ for the most important variable) together with the classification success of the model based on internal cross-validation.

Because seabird tracking data can be highly auto- correlated in space and time, we evaluated whether the random forest model was effective in capturing the spatial and temporal variation in the data using the included environmental variables. We tested for spatial autocorrelation in model residuals by calculating Moran's I (Moran 1950) for the 50 nearest neighbouring grid cells in each month using the function 'moran.test' in the R-package 'spdep'. Moran's I ranges from -1 (perfect dispersion) to +1 (perfect correlation), with 0 indicating complete lack of auto- correlation, and we concluded that the random forest model adequately accounted for spatial autocorrelation in the data if the absolute value of Moran's I of residuals was $<0.1$.

Algorithmic models can overfit the data, and we therefore externally validated each model using data from the other colony to assess whether the ecological relationships identified by the random forest model were generalisable across the tropical Atlantic (Elith \& Leathwick 2009, Oppel et al. 2012, Torres et al. 2015). We evaluated what proportion of St Helena locations were accurately classified by the model trained with data from lles de la Madeleine, and vice versa, and report the classification success of these external validations.

\section{RESULTS}

\section{Ethics}

On Madeleine, some birds failed during the study period but the percentage of tracked birds that failed to hatch (25\%) or to fledge $(16 \%)$ did not differ from those found for the control group ( 0 and $25 \%$, respectively) (hatching $\times 21=2.782, \mathrm{~N}=41, \mathrm{p}=0.095$; fledging $\times 21=0.065, N=35, p=0.799)$. Similarly, on St Helena, tracked birds that failed to hatch $(25 \%)$ or to fledge $(88.9 \%)$ did not differ from those found for control birds (53.8 and 33.3\%, respectively) (hatching $x 21=1.129, N=24, p=0.288$; fledging $x 21$ $=2.813, \mathrm{~N}=15, \mathrm{p}=0.094)$. Chick or adult mass between tracked and control birds did not differ significantly (chick mass tracked $=706 \pm 49.93 \mathrm{~g}$; untracked $=692.86 \pm 89.2 \mathrm{~g}$; t4.89 $=-0.169, \mathrm{p}=0.873$; adult mass tracked $=614.63 \pm 46.21 \mathrm{~g}$; untracked $596.86 \pm$ $51.21 \mathrm{~g} ; \mathrm{t} 56.95=1.367, \mathrm{p}=0.177$ ). Return rates to the breeding site the following year between tracked and untracked birds did not differ significantly (tracked $75.61 \%$; untracked birds 62.5\%; $\chi^{2} 1=0.438, N=57, p=0.508$ ).

\section{Diet identification through regurgitates}


The diet of tropicbirds on Madeleine during the breeding period was exclusively composed of 4 families of epipelagic fish: Belonidae (46.7\%), Exocoetidae (31.1\%), Carangidae (11.1\%) and Scombridae (11.1\%) (Table 1). Belonidae and Exocoetidae were consumed in greater frequency than Scombridae and Carangidae $(X 23=16.067$, $\mathrm{N}=45, \mathrm{p}=0.001)$. In terms of biomass, these 4 families were consumed in similar quantities: Belonidae (19.7\%), Exocoetidae (32.6\%), Carangidae (17.8\%) and Scombridae (29.2\%), although the proportion of Scombridae and Exocoetidae was slightly higher than that of the other 2 families $(x 23=8.17, N=111, p=0.04)$. The species that occurred in the diet inhabit the surface layer to $100 \mathrm{~m}$ depth (Table 1). These fish families include a number of species consumed by tropicbirds that have disparate commercial value, ranging from minor commercial value (Exocoetidae) to high commercial value (Carangidae and Scombridae) (Table 1). In 2015, fisheries captured $12174.08 \mathrm{t}$ of Scomber japonicus, $515.92 \mathrm{t}$ of $\mathrm{S}$. scomberus, $5129.03 \mathrm{t}$ of Caranx rhonchus and $10362.37 \mathrm{t}$ of Trachurus trecae in the EEZ of Senegal (DPM 2015).

Table 1. Summary of prey items from diet samples of red-billed tropicbirds on Madeleine ( $\mathrm{N}$ : number of specimens obtained). The commercial value of each species/family, depth range in which the species are most commonly found and the source of information are also presented 
Fig. 2. Red-billed tropicbirds foraging trips during incubation and brooding periods in $(A)$ Madeleine (10 incubating trips, 12 brooding trips) and (B) St Helena (6 incubating trips, 9 brooding trips). Red (black) lines indicate incubating (brooding) trips, dark blue shows the isobath at $200 \mathrm{~m}$, yellow star is the breeding colony

\section{Foraging parameters}

From the 41 deployments on Madeleine and 24 on St Helena, we could only obtain 22 and 15 complete foraging trips, respectively, due to loss of the devices. Of the 22 complete trips conducted by Madeleine tropicbirds, all headed in a westerly direction (Fig. 2A), whereas St Helena tropicbirds always headed north of the island (Fig. 2B). The best model explaining the maximum distance from the colony included colony and breeding stage, as well as the interaction between them (Akaike weight $=1$; interaction t33.02 $=5.26, p<0.001$ ). We found that the maximum distance from the colony was on average shorter for tropicbirds from Madeleine than for those from St Helena during incubation (Table 2; $\mathrm{t} 1,13=53.85, \mathrm{p}<0.001$ ), but did not differ during brooding (t20.01 $=1.12, p=0.27$ ). On St Helena, maximum distance from the colony was on average greater during the incubation stage than during brooding (Table 2; t12.99 $=6.07, \mathrm{p}<$ 0.001 ), although it did not differ between breeding stages on Madeleine ( $\mathrm{t} 19.68=1.16$, $\mathrm{p}=0.26)$. Regarding trip duration, the best model also included colony and breeding stage and the interaction between them (Akaike weight $=0.86$; interaction $t_{32.99}=2.83$, $p=0.01)$. Trip duration was shorter on Madeleine than on St Helena during incubation (Table 2; $t_{1,13}=13.51, \mathrm{p}=0.003$ ), but did not differ during brooding (Table $2 ; t_{20}=-0.45$, $p=0.66$ ). On St Helena, trip duration was on average larger during incubation than brooding (Table $2 ; t_{13}=7.23, p<0.001$ ), and on Madeleine trip duration was marginally longer in incubation than in brooding $\left(t_{19.99}=2.08, p=0.05\right)$. Regarding distance travelled, the best model included colony and breeding stage and the interaction between them (Akaike weight $=0.98$; interaction $t_{33}=3.36, p=0.002$ ). Distance travelled was shorter on Madeleine than on St Helena during incubation $\left(t_{1,13}=22.05, p\right.$ $<0.001)$, but not during brooding $\left(t_{20.15}=-0.08, p=0.94\right)$. Distance travelled was on average larger during incubation than brooding on St Helena $\left(t_{12.99}=6.2, p<0.001\right)$, but not on Madeleine $\left(t_{19.91}=1.63, p=0.12\right)$.

The size of the home range (95\% KDE) foraging area was greater on St Helena than on Madeleine $\left(F_{1,35}=8.25, p=0.01\right.$; Fig. 3). Foraging grounds in both colonies completely overlapped with the EEZs (Fig. 3).

Table 2. Total distance covered, maximum distance, duration and size of the area with $95 \%$ kernel density estimations during incubation and brooding stages of red-billed tropicbirds (mean $\pm \mathrm{SE}$ ) on Madeleine and St Helena. N: number of foraging trips, tkm2: thousands of km2 
Fig. 3. Kernel density of red-billed tropicbird foraging areas during incubation and brooding overlapped to exclusive economic zones (EEZs) in (A) Madeleine (22 for-aging trips) and (B) St Helena (15 foraging trips). Dashed black line is the $200 \mathrm{~m}$ iso- bath, solid black lines mark the EEZ, yellow star indicates the breeding colony

\section{Environmental variables}

There was strong statistical support for environ- mental differences between locations classified as 'travelling' and 'foraging', but the magnitude of the differences and the explanatory power of all environ- mental variables were small (Fig. S4 in Supplement 4; Table 3). Tropicbirds foraged in warmer and much more nutrient-rich and shallower stratified water off the coast of Madeleine compared to St Helena (Table 3), where the environment is characterized by much deeper water with steeper seafloor slopes and a greater number of distinct seamounts (Table 3). Distance to the colony and the number of Scombridae species had the greatest explanatory power in GLMMs (Table 3), and indicated that foraging locations were on average farther from the colony than travelling 
The random forest models were able to distinguish foraging from random background locations based on environmental variables, with very good classification success for both St Helena (misclassification rate from internal cross-validation; foraging: $6.6 \%$, background: $3.1 \%$ ) and Madeleine (foraging: $1.8 \%$, background: $17.4 \%$ ). There was no spatial autocorrelation in model residuals (Moran's / for St Helena:-0.011 to 0.098, for Madeleine: -0.005 to 0.015 ), indicating that the available environmental variables adequately captured the spatial variation in the data. The most important predictor variables differed be- tween colonies, and only distance to colony achieved $>80 \%$ relative importance at both colonies (Table 4); the richness of Scombridae and salinity were the most important variables around St Helena, while chl a concentration and distance to colony were the most important variables off the coast of Madeleine (Table 4; Fig. S5 in Supplement 4). Tropicbirds appeared to forage in waters with a greater richness of Scombridae around St Helena, but with an inter- mediate richness of these predatory fish and with intermediate chl a concentration off the coast of Madeleine (Fig. S5). At both colonies, more than 5 predictor variables achieved a relative variable importance $>50 \%$, indicating that foraging locations are unlikely to be determined by simple environmental gradients or features. Despite the excellent classification success in internal cross-validation, the models were not transferable to another spatially segregated colony in the Atlantic Ocean, likely because of major environmental differences between the colonies in bathymetry, chl a concentration, sea surface temperature and mixed layer depth. The misclassification rate for foraging locations from St Helena, when predicted from the model trained with data from Madeleine was $100 \%$. For Madeleine, locations predicted from the model trained with data from St Helena was $87.6 \%$. This occurred because each colony-specific model was too closely fitted to the environmental data and predicted either universally high (St Helena to Madeleine) or universally low (Madeleine to St Helena) suitability for foraging at the other colony.

Table 3. Mean \pm SD of environmental conditions at foraging and travelling locations of red-billed tropicbirds tracked from lles de la Madeleine and St Helena during the breeding season in 2015/2016 (incubation and chick-rearing combined); n: number of locations from which environmental data were available, R2: proportion of variance explained by the generalised linear mixed model with a colony $\times$ environment interactive fixed effect. The $p$-value indicates whether the environmental para- meter in the model is different from 0 . SST: sea surface temperature. 
ve round a nigner proportion or resting auring incuidation tnan auring prooaing $\left(l_{17.79}=\right.$

$2.78, p=0.01$ ), and a lower proportion of travelling during incubation than brooding

$\left(t_{19.34}=-2.53, p=0.02\right)$. We did not find a significant difference in the proportion of foraging between breeding stages $\left(t_{18.34}=-1.34, p=0.19\right)$. Tropicbirds on Madeleine rested mainly during the night and midday and showed travelling and foraging peaks around 08:00 and 19:00 h, generally matching with sunrise and sunset periods (Fig. 4).

\section{DISCUSSION}

This study provides the first data on the feeding ecology of red-billed tropicbirds in the eastern tropical Atlantic where the species has been poorly studied. We provide the first insights on the diet, daily activity patterns, foraging movements and feeding habitat selection of this species in the Atlantic and show how the foraging behaviour of tropicbirds can vary substantially between 2 areas with contrasting oceanographic conditions.

On Madeleine, red-billed tropic- birds fed exclusively on epipelagic fish of Belonidae Exocoetidae, Carangidae and Scombridae during their breeding period. This diet contrasts with that described for the same species in the Gulf of California and Trinidad and Tobago; these more oceanic environments provided a diet that was composed not only of fish but also squid (Castillo- Guerrero et al. 2011). The first 3 families are typically predated by tropical seabirds in association with large sub-surface predators during the day (Spear et al. 2007). Indeed, Madeleine birds showed mainly diurnal foraging activity patterns, with most of the resting taking place at night, but also with a peak of resting during the central and hottest hours of the day. This result aligns with that of red-tailed tropicbirds Phaethon rubricauda on Christmas Island during incubation (Sommerfeld \& Hennicke 2010). In the eastern Pacific, $46 \%$ of the feeding red-billed tropicbirds were associated with sub-surface predators or travelling cetaceans for feeding (Spear \& Ainley 2005b). On Madeleine, the shelf break is less than $100 \mathrm{~km}$ from the breeding colony, and tropicbirds mainly foraged on the shelf slope and beyond. The same foraging grounds are also exploited by Cape Verde shearwaters Calonectris edwardsii during their incubation period in June (Paiva et al. 2015). Indeed, seabird species diversity and abundance in the Canary Current generally peak within $20 \mathrm{~km}$ of either side of the shelf break (Camphuysen et al. 2013). In the Canary Current, the megafauna also concentrates around the shelf break (Zeeberg et al. 2006, Camphuysen et al. 2013). Altogether, these patterns indicate that the association with subsurface predators on the shelf break in front of Madeleine takes place during the day and might be an important tropicbird feeding strategy.

This area is also important for small migratory epipelagic species, such as horse mackerel (Trachurus spp.), that are particularly abundant in winter and early spring (Arístegui et al. 2009) when local upwelling is more intense (Menna et al. 2016). This may explain why tropicbird breeding peaks at this time (Diop et al. in press). Although

tropicbirds in Senegal feed in areas with artisanal gillnets and high demersal trawler activity, which discard around $40 \%$ of their catch (Belhabib et al. 2014), the diet composition indicates that tropicbirds do not rely on demersal discards. However, the 
possibility that tropıcbirds may partly feed on discards cannot be excluded, since large pelagic trawlers fishing on small pelagic fish also operate in the area and may discard pelagic species found in the diet of the tropicbirds (ter Hofstede \& Dickey- Collas 2006).

One of the major drivers of foraging behaviour is the breeding stage, since the energy demands and the breeding duties change across the breeding sea- son, limiting foraging in time and space (Phillips et al. 2017). In red-billed tropicbirds, foraging distance, foraging range, trip duration, distance travelled and depth of the foraging areas were greater during incubation than during brooding. These variations are usually attributed to the constraints of the brooding behaviour, when adults are forced to forage on a possibly suboptimal area close to the colony to ensure small chicks are fed frequently (Phillips et al. 2017). During brooding, foraging adults need to meet the energy requirements of their chicks, forcing birds to increase their effort. In agreement, we found tropic- birds spending less time resting during brooding than during incubation trips, whereas travelling was higher during brooding than during incubation. Such changes are common in albatrosses, petrels and penguins (Phillips et al. 2017), and have previously been noted in tropicbirds (Sommerfeld \& Hennicke 2010).

Oceanographic conditions at regional scales may play an important role in the foraging behaviour of tropical seabirds (Hennicke \& Weimerskirch 2014, McDuie et al. 2015, 2018, McDuie \& Congdon 2016, Weimerskirch et al. 2016, Miller et al. 2018). The more southerly St Helena is remote and surrounded by oceanic waters that are almost exclusively used by seabirds from this island, where the predictability and abundance of prey is presumably lower than on the permanent upwelling system of the African Shelf (Weimerskirch 2007, Harding et al. 2013). This would explain why net primary productivity and chl a con- centration of waters used by the tropicbirds from Madeleine were, respectively, 3- and 7-fold greater than those used by birds from St Helena, which may indicate lower food availability in the latter locality. This difference in food availability probably explains a greater foraging effort (trip duration and distance travelled) of tropicbirds breeding on St Helena and a stronger attraction to areas with the greatest species richness of Scombridae than those on Madeleine. However, overall the environmental variables had only limited power to explain where tropicbirds searched for food, and distance to the colony was one of the most important predictors at both colonies (Table 4), similar to other tropical seabirds (Oppel et al. 2017). In the case of Madeleine, tropicbirds did not exploit upwelling colder waters of the continental shelf and mainly foraged westwards on the shelf slope and be- yond, possibly to feed in association with subsurface predators, as explained above. However, tropicbirds on Madeleine did not associate with species richness of Scombridae, although this might be because only a single or few species of tuna might be abundant in the area. On St Helena, tropicbirds showed a stronger directional bias in their distribution than the birds near Africa, despite a much larger area of available open ocean over which they may theoretically have dispersed. In contrast to masked boobies Sula dactylatra of St Helena, which used waters all around the island (Oppel et al. 2015), tropicbirds always travelled to the north. Several underwater seamounts exist be- tween St Helena and

Ascension, $1200 \mathrm{~km}$ to the north-east, and seamounts may attract some marine top predators (Morato et al. 2008). However, tropic birds from St Helena did not appear to spend more time in the vicinity of seamounts (Fig. 3). The birds we tracked all breed on the north and north-eastern coast of St Helena, and other tropicbird colonies exist on 
the west and south coasts, but those birds nest on precipitous cliffs and were therefore not accessible for sampling. Although the tropicbird colonies on St Helena are generally small (10-30 pairs), it is possible that there is spatial partitioning at sea, and the birds we tracked therefore avoided marine areas to the south of the island presumably used by birds breeding in other colonies around St Helena (Ceia et al. 2015). An alternative explanation for the north- ward movement could be the prevalent gradient in water temperature, with warmer waters north of St Helena than south of the island. St Helena is the southernmost breeding locality of the species in the Atlantic Ocean, and the preferred prey of tropicbirds or the tuna they associate with may be mostly found in warmer waters north of the island.

Table 4. Relative importance of environmental predictor variables to distinguish between redbilled tropicbird foraging locations and the general environment (random background locations) around lles de la Madeleine and St Helena during the breeding season in 2015/2016. Variable importance is derived from a permutation procedure based on a random forest algorithm, where the increase in the mean squared error (MSE) indicates the decrease in classification accuracy when a variable is randomly permuted. Relative importance is scaled to $100 \%$ for the most important variable.

Fig. 4. Behavioural modes throughout the day during the breeding period of red-billed tropicbirds (incubation and brooding) on Madeleine. Dark grey areas correspond to darkness, light grey areas to sunrise and sunset periods and lightest grey areas to daylight. Orange represents resting, red is foraging, and blue is relocation.

One potential threat for tropicbirds is the inter- action with fisheries. The prey of tropicbirds are also targeted by regional fisheries, which may result in negative interactions (Zydelis et al. 2013). On Madeleine, the foraging grounds of tropicbirds are

not within a marine protected area. Indeed, the only protection is the $50 \mathrm{~m}$ seawards extension of Madeleine protected area around the colony (DPN 2010), which is clearly too small for this species (Oppel et al. 2018). However, the foraging grounds completely overlap with that of the EEZ of Senegal and sur- rounding countries. Artisanal fisheries, 
for tropicbirds, since this fishery uses horse mackerel as bait (Sow 2016). How- ever, worldwide by-catch of tropicbirds seems to be scarce, only documented on 2 occasions (Pott \& Wiedenfeld 2017), and it is unlikely that fisheries operating in the area cause a direct impact on tropicbirds. Senegalese fisheries may also pose an indirect competitive threat to tropicbirds (Cury et al. 2011), as Cunene horse mackerel T. tracea, an important component of tropicbird diet, are of high commercial value and are extensively fished (Mbengue 2012, DPM 2015). In fact, small pelagic fish stocks in Senegal are over-exploited, and the ecosystem is deteriorating due to climate change (Belhabib et al. 2014, Coll et al. 2016), enhancing interspecific competition with seabirds, which could ultimately affect the productivity and viability of their populations (Arístegui et al. 2009, Sambe et al. 2016). In addition, tuna catches in the Canary Current seem to be dropping for at least 2 of the 3 most common species in the area (Braham \& Corten 2015), which may reduce feeding opportunities for tropic- birds or, alternatively, increase pelagic fish abundance due to reduced predation pressure (Montevecchi 2002). On the other hand, fishing activities around St Helena are regulated and licensed to com- ply with the objectives of the marine protected area and exploit inshore waters not far from the island (St Helena Government 2016). These only partially over- lap with the tropicbird's foraging grounds, which may reduce this competitive interaction.

Ultimately, our study reveals that red-billed tropic- birds can breed in localities that display contrasting marine environments. The differential colony-specific foraging movements and feeding habitat selection demonstrate that patterns of activity and environ- mental characteristics cannot easily be extrapolated across breeding colonies. Finally, foraging grounds of tropicbirds on Madeleine completely overlap with EEZs of surrounding countries, which indicates that the conservation of the species totally depends on national governments. Indirect competition with fisheries that overexploit the prey of tropicbirds and tar-get large sub-surface predators, in conjunction with the increase in SST in the Canary Current, may be of particular concern for tropicbirds. Further research is needed to fully understand the impact of these at- sea threats on the western African population of this species.

Acknowledgements. The work on Madeleine was conducted as part of the Alcyon project funded by MAVA Foundation and implemented by FIBA and thereafter by BirdLife International. We thank the Direction des Parcs Nationaux du Senegal (DPN) for granting us a permit (no. 001471/2015) for access to the National Park of Madeleine Islands and the staff of the park for their help during the fieldwork and to the Ministerio de Economía y Competitividad and Fondos FEDER (CGL2013-42585-P and CGL2016$78530-\mathrm{R})$ for funding support. We also thank Sergi Torné for his help in prey identification from regurgitations, Sara Saldanha for the English revision and Paul Robinson for his support on the initial stage of this study. L.Z. was supported by a PhD grant from the Spanish government (Formacion de Profesorado Universitario;

FPU15/01927). St Helena Government thanks Enterprise St Helena for funding the work and the Royal Society for the Protection of Birds (RSPB) for technical sup- port. Thanks also to the volunteers and staff of the St Helena Nature Conservation Group (SNCG), the St Helena Trust (SHNT) and the Ascension Island Conservation Department. 


\section{LITERATURE CITED}

Arístegui J, Barton ED, Álvarez-Salgado XA, Santos AMP and others (2009) Subregional ecosystem variability in the Canary Current upwelling. Prog Oceanogr 83:33-48

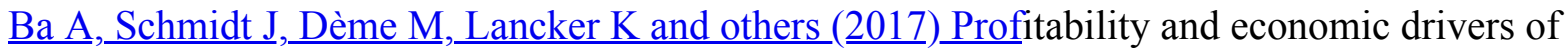
small pelagic fisheries in West Africa: a twenty-year perspective. Mar Policy 76: 152-158

Barton K (2018) MuMIn: multi-model inference. R Package 1.42.1. https://CRAN.Rproject.org/package $=$ MuMIn

Bates D, Maechler M, Bolker B, Walker S (2015) Fitting linear mixed-effects models using lme4. J Stat Softw 67:1-48

Beard A, Clingham E, Henry L (2013) St Helena seabird re- port. Environmental Management Division, Jamestown, St Helena Island

Belhabib D, Koutob V, Sall A, Lam VWY, Pauly_ D (2014). Fisheries catch misreporting and its implications: the case of Senegal. Fish Res 151:1-11

Bellemans MS, Sagna A, Fischer W, Scialabba N (1988) Guide des ressources halieutiques du Sénégal et de la Gambie (espèces marines et d'eaux saumatres). Organi- sation des Nations Unies pour l'Alimentation et l'Agri- culture (FAO), Rome

Bennison A, Bearhop S, Bodey TW, Votier SC and others (2018) Search and foraging behaviors from movement data: a comparison of methods. Ecol Evol 8:13-24

Bertrand S, Joo R, Arbulu Smet C, Tremblay_Y, Barbraud C, Weimerskirch H (2012) Local depletion by a fishery can affect seabird foraging. J Appl Ecol 49:1168-1177

BirdLife International (2018) Species factsheet: Phaethon aethereus. http://datazone.birdlife.org/species/factsheet/22696637(accessed 9 September 2018)

Braham CB, Corten A (2015) Pelagic fish stocks and their response to fisheries and environmental variation in the Canary Current large marine ecosystem. In: Valdés L, DénizGonzález I (eds) Oceanographic and biological features in the Canary Current large marine ecosystem. UNESCO, Paris, p 196-214

Breiman L (2001) Random forests. Mach Learn 45:5-32 Camphuysen CJ, van Spanje TM, Verdaat JP (2013) Ship- based seabird and marine mammal surveys off Mauritania, Nov-Dec

2012: cruise report. NIOZ, Den Burg

Campos LFAS, Andrade AB, Bertrand S, Efe MA (2018) For- aging behavior and at-sea distribution of white-tailed tropicbirds in tropical ocean. Braz J Biol 78:556-563 
tropicbird Phaethon aethereus under contrasting environmental conditions in the Gulf of California. Ardea 99:61-71

Ceia FR, Paiva VH, Ceia RS, Hervías S, Garthe S, Marques JC, Ramos JA (2015) Spatial foraging segregation by close neighbours in a wide-ranging seabird. Oecologia 177:431-440

Coll M, Shannon LJ, Kleisner KM, Juan-Jordá MJ and oth- ers (2016) Ecological indicators to capture the effects of fishing on biodiversity and conservation status of marine ecosystems. Ecol Indic 60:947-962

Cury PM, Boyd IL, Bonhommeau S, Anker-Nilssen T and others (2011) Global seabird response to forage fish depletion — one-third for the birds. Science 334:1703-1706

Cutler DR, Edwards TC, Beard KH, Cutler A, Hess KT, Gibson J, Lawler JJ (2007) Random forests for classification in ecology. Ecology 88:2783-2792

Dias MP, Granadeiro JP,_Catry P (2012) Working the day or the night shift? Foraging schedules of Cory's shearwaters vary according to marine habitat. Mar Ecol Prog Ser 467: 245-252

Diop N, Ba CT, Ndiaye PI, Militão T, González-Solís J (in press) Population size and breeding phenology of red- billed tropicbirds (Phaethon aethereus) on Iles de la Madeleine, Senegal. Waterbirds

Dodge S, Bohrer G, Weinzierl R, Davidson S and others (2013) The environmental-data automated track annotation (Env-DATA) system: linking animal tracks with environmental data. Mov Ecol 1:3

DPM (Direction des Pêches Maritimes) (2015) Résultats généraux des pêches maritimes. DPM, Dakar

DPN (Direction des Parcs Nationaux) (2010) Plan de estion du Parc National des Iles de La Madeleine (2010-2014). DPN, Dakar

Elith J, Leathwick JR (2009) Species distribution models: ecological explanation and prediction across space and time. Annu Rev Ecol Evol Syst 40:677-697

Froese R, Pauly D (2017) FishBase. www.fishbase.org (accessed 28 Dec 2017)

Garriga J, Palmer JRB, Oltra A, Bartumeus F (2016) Expectation-maximization binary clustering for behavioural annotation. PLOS ONE 11(3):e0151984

Grecian WJ, Witt MJ, Attrill MJ, Bearhop S and others (2016) Seabird diversity hotspot linked to ocean productivity in the Canary Current Large Marine Ecosystem. Biol Lett 12:2016.0024

Harding $\underline{A}, \underline{\text { Paredes R}}, \underline{\text { Suryan R }}, \underline{\text { Roby }} \mathrm{D}$ and others $(2013)$. Does location really matter? An inter-colony comparison of seabirds breeding at varying distances from productive 
Harris MP (1969) Factors influencing the breeding cycle of the red-billed tropicbird in the Galapagos Islands. Ardea 57:148-157

Hennicke JC, Weimerskirch H (2014) Coping with variable and oligotrophic tropical waters: foraging behaviour and flexibility of the Abbott's booby Papasula abbotti. Mar Ecol Prog Ser 499:259-273

Hochachka WM, Caruana R, Fink D, Munson ART, Riedewald M, Sorokina D, Kelling S (2007) Data-mining discovery of pattern and process in ecological systems. J Wildl Manag $71: 2427-2437$

Kaschner K, Kesner-Reyes K, Garilao C, Rius-Barile J, Rees T, Froese R (2016) AquaMaps: predicted range maps for aquatic species. www.aquamaps.org (accessed 13 July 2018)

Le Corre M (1997) Diving depths of two tropical Pelecaniformes: the red-tailed tropicbird and the red-footed booby. Condor 99:1004-1007

Le Corre M, Cherel Y, Lagarde F, Lormée H, Jouventin P (2003) Seasonal and inter-annual variation in the feeding ecology of a tropical oceanic seabird, the red-tailed tropicbird Phaethon rubricauda. Mar Ecol Prog Ser 255: 289-301

Lee DS, Walsh-McGehee M (2000) Population estimates, conservation concerns, and management of tropicbirds in the Western Atlantic. Caribb J Sci 36:267-279

Lewis F, Butler A, Gilbert L (2011) A unified approach to model selection using the likelihood ratio test. Methods Ecol Evol 2:155-162

Lewison R, Oro D, Godley BJ, Underhill L and others (2012). Research priorities for seabirds: improving conservation and management in the 21st century. Endang Species Res 17:93-121

Liaw A, Wiener M (2002) Classification and regression by randomForest. R News 2:18-22

Mannocci L, Laran S, Monestiez P, Dorémus G, Van Canneyt O, Watremez P, Ridoux V (2014) Predicting top predator habitats in the Southwest Indian Ocean. Ecography 37: 261-278

Mbengue M (2012) Rapport de capitalisation des initiatives de gestion des petits pélagiques. CRSP012, Dakar

McDuie F, Congdon BC (2016) Trans-equatorial migration and non-breeding habitat of tropical shearwaters: implications for modelling pelagic Important Bird Areas. Mar Ecol Prog Ser

550:219-234

McDuie F, Weeks SJ, Miller MGR, Congdon BC (2015) Breeding tropical shearwaters use distant foraging sites when self-provisioning. Mar Ornithol 43:123-129

McDuie F, Weeks SJ, Congdon BC (2018) Oceanographic drivers of near-colony seabird foraging site use in tropical marine systems. Mar Ecol Prog Ser 589: 209-225 
Menna M, Faye S, Poulain PM, Centurioni L and others (2016) Upwelling features off the coast of north-western Africa in 2009-2013. Boll Geofis Teor Appl 57:71-86

Miller MGR, Carlile N, Phillips JS, McDuie F, Congdon BC (2018) Importance of tropical tuna for seabird foraging over a marine productivity gradient. Mar Ecol Prog Ser 586:233-249

Montevecchi WA (2002) Interactions between fisheries and seabirds. In: Schreiber EA, Burger J (ed) Biology of marine birds. CRC Press, Boca Raton, FL, p 527-557

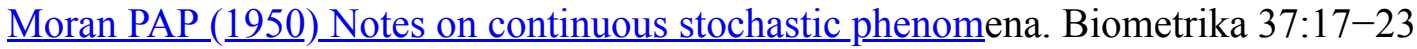

Morato T, Varkey DA, Damaso C, Machete M and others (2008) Evidence of a seamount effect on aggregating visitors. Mar Ecol Prog Ser 357:23-32

Nakagawa S, Schielzeth H (2013) A general and simple method for obtaining $\mathrm{R}_{2}$ from generalized linear mixed- effects models. Methods Ecol Evol 4:133-142

Oppel S, Meirinho A, Ramírez I, Gardner B, O’Connell A, Miller PI, Louzao M (2012) Comparison of five modelling techniques to predict the spatial distribution and abundance of seabirds. Biol Conserv 156:94-104

Oppel S, Beard A, Fox D, Mackle E and others (2015) Foraging distribution of a tropical seabird supports Ashmole's hypothesis of population regulation. Behav Ecol Socio- biol 69:915-926

Oppel S, Weber S, Weber N, Fox D and others (2017) Seasonal shifts in foraging distribution due to individual flexibility in a tropical pelagic forager, the Ascension frigatebird. Mar Ecol Prog Ser 585:199-212

Oppel S, Bolton M, Carneiro APB, Dias MP and others (2018) Spatial scales of marine conservation management for breeding seabirds. Mar Policy 98:37-46

Orta J (1992) Family Phaethontidae (tropicbirds). In: del Hoyo J, Elliott A, Sargatol J (ed) Handbook of the birds of the world. Lynx Edicions, Barcelona, p 280-289

Orta J, Jutglar F, Bonan A, Garcia EFJ, Kirwan GM, Boesman P (2016) Red-billed tropicbird (Phaethon aethereus). In: del Hoyo J, Elliott A, Sargatal J, Christie DA, de Juana E (eds) Handbook of the birds of the world alive. Lynx Edicions, Barcelona. www.hbw.com/node/52607 (accessed on 9 September 2016)

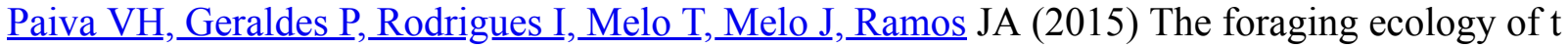

he endangered Cape Verde shearwater, a sentinel species for marine conservation off West Africa. PLOS ONE 10:e0139390

Péron C, Authier M, Gremillet D (2018) Testing the transfer- ability of track-based habitat models for sound marine spatial planning. Divers Distrib (in press) doi:10.1111/ ddi.12832 
Pinet P, Jacquemet S, Phillips RA, Le Corre M (2012) Sex- specific foraging strategies throughout the breeding season in a tropical sexually monomorphic small petrel. Anim Behav 83:979-989

$\underline{\text { Pollet IL, Hedd A }}$, Taylor PD, Montevecchi WA, Shutler D (2014) Migratory movements and wintering areas of Leach's storm-petrels tracked using geolocators. J Field Ornithol 85:321-328

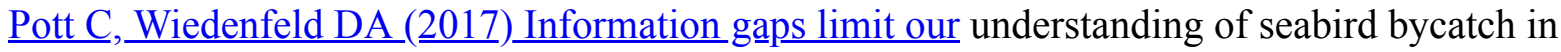
global fisheries. Biol Conserv 210:192-204

Prater T (2012) Important Bird Areas: St Helena. Br Birds 105:638-653

R Core Team (2016) R: a language and environment for statistical computing. R Foundation for Statistical Computing, Vienna

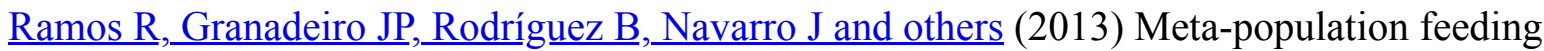
grounds of Cory's shear- water in the subtropical Atlantic Ocean: implications for the definition of Marine Protected Areas based on tracking studies. Divers Distrib 19:1284-1298

$\underline{\text { Sambe B }}$, Tandstad M, Maria A, Brown BE (2016) Variations in productivity of the Canary Current Large Marine Ecosystem and their effects on small pelagic fish stocks. Environ Dev $17: 105-117$

Seret B (1981) Poissons de Mer de L'ouest Africain Tropical. Orstom, Paris

Snow DW (1965) The breeding of the red-billed tropicbird in the Galapagos Islands. Condor 67:210-214

Soanes LM, Bright JA, Carter D, Dias MP and others (2016). Important foraging areas of seabirds from Anguilla, Caribbean: implications for marine spatial planning. Mar Policy $70: 85-92$

Sommerfeld J, Hennicke JC (2010) Comparison of trip dura- tion, activity pattern and diving behaviour by red-tailed tropicbirds (Phaethon rubricauda) during incubation and chick-rearing. Emu 110:78-86

Sow FN (2016) Distribution des captures et des tailles du voilier de l'atlantique (Istiophorus albicans) capture par la pêche artisanale au Sénégal. Collect Vol Sci Pap ICCAT 72:2083-2089

Spear LB, Ainley DG $(\underline{2005 a})$ At sea distributions and abundance of tropicbirds in the eastern Pacific. Ibis 147:353-366

Spear LB, Ainley_DG (2005b) At sea behaviour and habitat use by tropicbirds in the eastern Pacific. Ibis 147:391-407

Spear LB, Ainley DG, Walker WA (2007) Foraging dynamics of seabirds in the eastern tropical 
Pacific Ocean. Studies in Avian Biology, No. 35. Cooper Ornithological Society, Los Angeles, CA

St Helena Government (2016) St Helena Marine Management Plan. Environmental Management Division, James- town, St Helena

Stonehouse B (1962) The tropicbirds (Genus Phaethon) of Ascension Island. Ibis 103:124-161

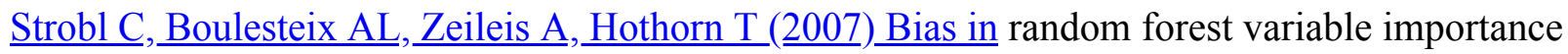
measures: illustrations, sources and a solution. BMC Bioinformatics 8: 25-45

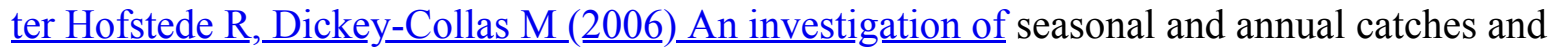
discards of the Dutch pelagic freezer-trawlers in Mauritania, Northwest Africa. Fish Res $77: 184-191$

Thiaw M, Auger PA, Ngom F, Brochier T, Faye S, Diankha O, Brehmer P (2017) Effect of environmental conditions on the seasonal and inter annual variability of small pelagic fish abundance off North West Africa: the case of both Senegalese sardinella. Fish Oceanogr 26: $583-601$

Torres LG, Sutton PJH, Thompson DR, Delord K and others (2015) Poor transferability of species distribution models for a pelagic predator, the grey petrel, indicates contrasting habitat preferences across ocean basins. PLOS ONE 10:e0120014

Wakefield ED, Phillips RA, Matthiopoulos J (2009)_Quantifying habitat use and preferences of pelagic seabirds using individual movement data: a review. Mar Ecol Prog Ser 391:165-182

Wakefield ED, Owen E, Baer J, Carroll MJ and others (2017). Breeding density, fine scale tracking and large scale modeling reveal the regional distribution of four seabird species. Ecol Appl 27:2074-2091

$\underline{\text { Weimerskirch H }}$ (2007) Are seabirds foraging for unpredictable resources? Deep-Sea Res II 54:211-223

Weimerskirch H, Bishop C, Jeanniard-du-Dot T, Prudor A, Sachs G (2016) Frigate birds track atmospheric conditions over months-long transoceanic flights. Science 353: 74-78

Wood AG, Naef-Daenzer B, Prince PA, Croxall JP (2000). Quantifying habitat use in satellitetracked pelagic seabirds: application of kernel estimation to albatross locations. J Avian Biol $31: 278-286$

Yates KL, Bouchet PJ, Caley MJ, Mengersen K and others (2018) Outstanding challenges in the transferability of ecological models. Trends Ecol Evol 33:790-802

Zeeberg J, Corten A, de Graaf E (2006) Bycatch and release of pelagic megafauna in industrial trawler fisheries off Northwest Africa. Fish Res 78:186-195

$\underline{\text { Zydelis R }}, \underline{\text { Small C }}, \underline{\text { French G }}(\underline{2013})$ The incidental catch of seabirds in gillnet fisheries: a global review. Biol Conserv 162:76-88 
